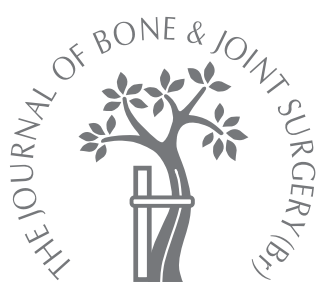

M. P. Jackson, S. A. Sexton, E. Yeung, W. L. Walter, W. K. Walter, B. A. Zicat

From Sydney Hip and Knee Surgeons, Sydney, Australia

\title{
The effect of obesity on the mid-term survival and clinical outcome of cementless total hip replacement
}

The outcome of total hip replacement (THR) is potentially affected by the body mass index (BMI) of the patient. We studied the outcome of 2026 consecutive primary cementless THRs performed for osteoarthritis. The mean follow-up was 6.3 years ( 0 to 11.71 ) and no patient was lost to follow-up for survival analysis. The patients were divided into two groups according to their BMI as follows: non-obese (BMI $<30 \mathrm{~kg} / \mathrm{m}^{2}$ ) and obese $\left(B M I \geq 30 \mathrm{~kg} / \mathrm{m}^{2}\right)$.

The obese patient undergoing surgery was found to be significantly younger $(p<0.001)$. The log-rank test for equality of survival showed no difference in the mid-term survival ( $p=0.552)$ with an estimated survival at 11 years of $95.2 \%(95 \% \mathrm{Cl} 92.5$ to 98.0$)$ in the nonobese and $96.7 \%(95 \% \mathrm{Cl} 94.9$ to 98.5$)$ in the obese groups. The clinical and radiological outcome was determined in a case-matched study performed on 134 obese individuals closely matched with 134 non-obese controls. The non-obese group was found to have a significantly higher post-operative Harris hip score $(p<0.001)$ and an increased range of movement, but overall satisfaction with surgery was comparable with that of the obese patients. Radiological analysis of the acetabular and femoral components showed no significant differences with regard to radiolucent lines, osteolysis, ingrowth of the femoral component, the acetabular inclination angle or alignment of the femoral component. Our results suggest that the survival of cementless THR is not adversely affected by obesity. Obese patients can therefore be counselled that despite a lower clinical score, they should expect to be satisfied with the result of their THR with a mid-term survival rate equivalent to that of non-obese patients.

There is an increasing awareness of the rise in obesity within the Western World and it has been described as reaching epidemic proportions. ${ }^{1}$ Obesity has been defined by the World Health Organisation ${ }^{1}$ as a body mass index (BMI) of over $30 \mathrm{~kg} / \mathrm{m}^{2}$. The impact that this will have on the health of future generations remains the subject of much debate. North American data have shown that the percentage of patients having a total hip replacement (THR) who are classified as obese has risen from $22.1 \%$ in 1990 to $33.8 \%$ in $2005 .{ }^{2}$ The mean BMI during this period rose from 26.8 to 29.2. A study from the United Kingdom has demonstrated a statistically significant correlation between a lower age at THR and an increasing BMI. ${ }^{3}$ It seems likely that both of these patterns are being repeated worldwide. It is important to determine the implications of these observations on the survival and outcome of THR in obesity. Despite this, there are only a limited number of studies $^{4-9}$ which have evaluated THR in the presence of obesity and these have had conflicting results. Furthermore, many have small numbers and short follow-up and data are even more sparse for cementless THR. ${ }^{8}$

Our aim was to review the mid-term survival and clinical and radiological outcome of a large group of patients who had undergone cementless THR and to compare the results in non-obese and obese patients.

\section{Patients and Methods}

We examined the results of 2140 consecutive primary cementless THRs which had been performed in 1773 patients with osteoarthritis between 1997 and 2006. All the procedures took place in a single hospital and surgery had been performed by one of two experienced surgeons (WKW, BAZ). THR was performed within a high air-flow environment through a posterior approach using similar operative techniques which remained constant throughout the period of study. All the patients had an ABG2 (Stryker, Mahwah, New Jersey) cementless femoral component implanted and 1931 also received an ABG2 (Stryker) cementless 
acetabular component. In the remaining 209 procedures cementless acetabular modular components of similar design were used. The ABG2 femoral component is of anatomical design, and is made of $\mathrm{a} \mathrm{Ti}_{12} \mathrm{Mo}_{6} \mathrm{Zr}_{2} \mathrm{Fe}$ alloy with a proximal metaphyseal hydroxyapatite (HA) coating. The acetabular component is made from a $\mathrm{TiA}_{6} \mathrm{~V}_{4}$ alloy and is hemispherical with an HA coating.

The patients's BMI was calculated from data recorded at the time of their pre-operative assessment which was generally undertaken two to four weeks before their operation. In our unit no patient was refused THR simply on the basis of a raised BMI and no other pre-operative selection criteria were applied. For the purposes of analysis the patients were then categorised into non-obese $(\mathrm{BMI}<30)$ and obese $(\mathrm{BMI}$ $\geq 30$ ) groups. The BMI data were incomplete for 114 patients which left 1659 patients (367 bilateral) with 2026 implants $(94 \%)$ available for analysis.

Of these 2026 THRs, all bearing combinations were included. There were $1757(86.7 \%)$ ceramic-on-ceramic (361 obese, 1396 non-obese), 140 (6.9\%) ceramic-onpolyethylene (28 obese, 112 non-obese) and 129 (6.4\%) metal-on-polyethylene (25 obese, 104 non-obese). The patients subsequently followed a standardised postoperative regime which incorporated chemical and mechanical thromboembolic prophylaxis and the administration of intravenous antibiotics for 48 hours. They were mobilised fully weight-bearing as tolerated under the supervision of a physiotherapist.

No individual was lost to follow-up as regards to survival of the implant and we were therefore able to include all the hips in the survival study. A case-matched study was subsequently performed on all the obese patients with THRs with a minimum follow-up of two years. We were able to match 134 obese patients with 134 non-obese patients with a THR on the basis of age to within one year, side of surgery, pre-operative diagnosis, operating surgeon, acetabular component, bearing configuration and the time to latest follow-up (within one year).

Consent was obtained for the use of anonymised information for ongoing research projects.

All clinical information, details of the operation and the results of clinical and radiological assessments were prospectively collected and recorded onto a database as part of routine follow-up. The data collectors (WLW, WKW, BAZ) were blinded to any particular study.

The clinical outcome was assessed using the Harris hip score $^{10}$ (HHS). The post-operative range of movement was evaluated separately. An additional satisfaction question was scored on a ten-point visual analogue scale in which no points indicated total dissatisfaction and ten points complete satisfaction. Radiological analysis of the components was performed on anteroposterior (AP) pelvic and AP/ lateral radiographs of the hip. These were scored by arthroplasty surgery fellows blinded to the patients' BMI and who were not involved in the initial surgery or clinical followup. The acetabular component was evaluated for the presence of radiolucent lines and osteolytic lesions as described by Johnston et $\mathrm{al}^{11}$ and the inclination angle of the implant was recorded. The femoral component was studied in each of the seven zones of Gruen, McNeice and Amstutz ${ }^{12}$ in regard to the development of radiolucent lines, osteolysis, femoral cortical hypertrophy, stress shielding and the presence of endosteal spot welds between the surface of the implant and the surrounding bone using the criteria of Engh, Massin and Suthers. ${ }^{13}$ We classified ingrowth of the femoral component as bony ingrowth, stable fibrous and loose fibrous, and the alignment as at either neutral or in varus or valgus.

Statistical analysis. The analysis was performed using SPSS software (SPSS Inc., Chicago, Illinois) and the results were compared using a combination of the paired and unpaired two-tailed $t$-tests, Fisher's exact test and the chi-squared test with a significance level set at 0.05 . Survival data were investigated using a log-rank test for the equality of survivorship with Kaplan-Meier curves with $95 \%$ confidence intervals (CI) generated using revision for any reason as the endpoint. A post hoc power analysis was performed with the alpha and beta levels set at 0.05 and 0.2 , respectively.

\section{Results}

The details of the 2026 implants are given in Table I. The mean age of obese patients undergoing THR was five years younger than that of non-obese patients $(\mathrm{p}<0.001)$. There was no significant difference in the proportions of men and women in the two groups $(\mathrm{p}=0.659)$. The mean follow-up for all patients was 6.3 years ( 0 to 11.71).

The details of the patients in the case-matched study are shown in Table II with the results in Table III. A statistically significant difference was found in the mean total HHS between the groups with the non-obese group showing a higher mean total overall $(\mathrm{p}<0.001)$. This consisted of significantly better scores in all individual parameters apart from the pain component. In addition, the independently assessed range of movement also showed significantly better hip flexion $(\mathrm{p}<0.001)$, adduction $(\mathrm{p}=0.011)$ and internal rotation $(\mathrm{p}=0.008)$ in the non-obese group. There was no statistically significant difference in abduction $(\mathrm{p}=0.192)$ or external rotation $(\mathrm{p}=0.250)$. Likewise no statistical difference was reported between the groups in the overall satisfaction with surgery $(\mathrm{p}=0.138)$.

Radiological analysis showed no significant differences between the two groups in the evaluation of the acetabular component with regard to radiolucent lines, osteolytic lesions or the inclination angle of the implant $(\mathrm{p}=0.433)$. Similarly, there were no significant differences on the femoral side with regard to the presence of radiolucencies $(\mathrm{p}=0.418)$, cortical hypertrophy $(\mathrm{p}=0.102)$, stress shielding $(\mathrm{p}=0.789)$, spot welds $(\mathrm{p}=0.178)$ or alignment of the component $(\mathrm{p}=0.343)$. All of the femoral components in both groups had radiological evidence of stable bony ingrowth. 
Table I. Details for survival analysis of the entire series

\begin{tabular}{|c|c|c|c|c|c|}
\hline \multirow[b]{2}{*}{ Total number implants (\%) } & \multirow{2}{*}{$\begin{array}{l}\text { All } \\
2026\end{array}$} & \multicolumn{2}{|c|}{ Non-obese } & \multicolumn{2}{|c|}{ Obese } \\
\hline & & 1612 & $(79.6)$ & 414 & $(20.4)$ \\
\hline Total number patients (\%) & 1659 & 1301 & $(78.4)$ & 358 & $(21.6)$ \\
\hline \multicolumn{6}{|l|}{ Gender (\%) } \\
\hline Male & 949 & 751 & $(79.1)$ & 198 & (20.9) \\
\hline Female & 1077 & 861 & (79.9) & 216 & $(20.1)$ \\
\hline Mean age in years (range) & 67 (24 to 93) & 68 & (24 to 93 ) & 63 & (24 to 89 ) \\
\hline Mean follow-up in years (range) & $6.3(0$ to 11.71$)$ & 6.4 & (0 to 11.71$)$ & 6.1 & (0 to 11.69 ) \\
\hline Mean body mass index (range) & $26.8(16.5$ to 53.5$)$ & 25.0 & (16.5 to 29.9$)$ & 33.8 & (30 to 53.5$)$ \\
\hline
\end{tabular}

Table II. Details for survival in the case-controlled study

\begin{tabular}{lrl}
\hline & Non-obese & Obese \\
\hline Total number & 134 & 134 \\
& & \\
Gender (\%) & 57 & 57 \\
$\quad$ Male & 77 & 77 \\
$\quad$ Female & $63.9(44$ to 79$)$ & 64.0 (43 to 79) \\
Mean age in years (range) & 5.1 (2 to 10.3) & 5.1 (2 to 10.1) \\
Mean follow-up in years (range) & 53.0 (18 to 29.9) & 33.4 (30 to 47.8) \\
Mean body mass index (range) & 25.0
\end{tabular}

The post hoc power analysis showed that we would detect with a certainty of $80 \%$ a clinically significant difference of the means for a $5^{\circ}$ difference in the range of movement, a $2^{\circ}$ difference in the radiological alignment, a twopoint difference in the HHS and a one-point difference in the satisfaction score.

There were 125 deaths and 56 revision procedures for any reason during the follow-up period. The 125 deaths were of 21 obese and 104 non-obese patients giving a crude mortality rate of $5.9 \%$ (21 of 358$)$ in the obese and $8.0 \%$ (104 of 1301) in the non-obese groups which did not differ significantly $(p=0.213)$. The mean interval to death after THR was also not significantly different with a mean of 3.8 years $(0.6$ to 10.2$)$ in the obese and 4.7 years $(0$ to 10.2$)$ in the non-obese groups $(\mathrm{p}=0.131)$. Of the 56 revisions, 13 were in obese and 43 in non-obese groups giving a crude revision rate of $3.1 \%$ (13 of 414 ) in the obese and $2.7 \%$ (43 of 1612) in the non-obese groups. This difference was not significant $(\mathrm{p}=0.614)$. The mean time to revision was 1.3 years $(0.1$ to 4.0$)$ in the obese and 2.6 years ( 0 to 10.7$)$ in the non-obese patients which was also not significant $(p=0.147)$. Of the 56 revision procedures, 33 were for periprosthetic fractures ( 6 obese), 11 for aseptic loosening (3 obese), eight for recurrent dislocation ( 3 obese), two secondary to component failure (both non-obese), one for deep sepsis (non-obese) and one for squeaking arising from the articulation (obese). The Kaplan-Meier survival analysis comparing the non-obese and obese patients with an endpoint as revision for any reason showed no significant difference between the groups $(\mathrm{p}=0.552)$. The estimated
Table III. Clinical results (mean, SD) in the hips in the case-matched groups

\begin{tabular}{lcrr}
\hline & Non-obese & Obese & p-value \\
\hline Harris hip score & & & \\
$\quad$ Total & $93.2(7.9)$ & $89.9(8.9)$ & $<0.001$ \\
Pain & $42.3(3.4)$ & $41.8(4.3)$ & 0.351 \\
Function & $31.0(3.9)$ & $29.6(4.7)$ & 0.006 \\
Activities & $11.7(2.6)$ & $10.6(2.5)$ & 0.001 \\
Range of movement & $8.2(1.0)$ & $10.6(1.0)$ & 0.020 \\
& & & \\
Hip flexion $\left({ }^{\circ}\right)$ & $122.5(18.1)$ & $113.1(16.9)$ & $<0.001$ \\
Abduction $\left({ }^{\circ}\right)$ & $32.5(6.9)$ & $31.0(10.8)$ & 0.192 \\
Adduction $\left({ }^{\circ}\right)$ & $25.2(6.1)$ & $23.2(6.7)$ & 0.011 \\
External rotation $\left({ }^{\circ}\right)$ & $23.6(9.1)$ & $24.7(8.9)$ & 0.250 \\
Internal rotation $\left({ }^{\circ}\right)$ & $14.0(8.5)$ & $11.2(7.9)$ & 0.008 \\
Satisfaction score $/ 10$ & $9.3(1.6)$ & $9.0(2.1)$ & 0.138 \\
\hline
\end{tabular}

chance of survival of the implant at 11 years for the nonobese group was $95.2 \%(95 \%$ CI 92.5 to 98.0$)$ and for the obese $96.7 \%$ (95\% CI 94.9 to 98.5 ) (Figs 1 to 3 ). The number of patients at risk at 11 years in the non-obese group was 57 and in the obese group 18 .

\section{Discussion}

Recent studies have shown an association between both the presence and the degree of obesity with the relative risk of subsequent THR. ${ }^{14,15}$ In the largest survival analysis to date we have shown that there was no significant difference between the non-obese and obese groups in mid-term survival with both achieving survival rates of over $95 \%$ at 11 years. On this evidence obese patients should not be denied THR simply on the basis of their obesity. Similar findings have been reported by Haverkamp et $\mathrm{al}^{4}$ for survival rates at ten years for cemented THR in obese patients. Likewise, McLaughlin and $\mathrm{Lee}^{5}$ found no difference in the outcome for cementless THR followed for a mean of 14.5 years in obese patients. However, both of these studies were performed on relatively small groups of 411 and 260 patients, respectively.

The matching of 134 non-obese and obese patients to reduce potential confounding variables allowed us to examine the benefit obtained in each group. The results showed that despite an equivalent survival, obese patients achieved a lower clinical score post-operatively, with all 


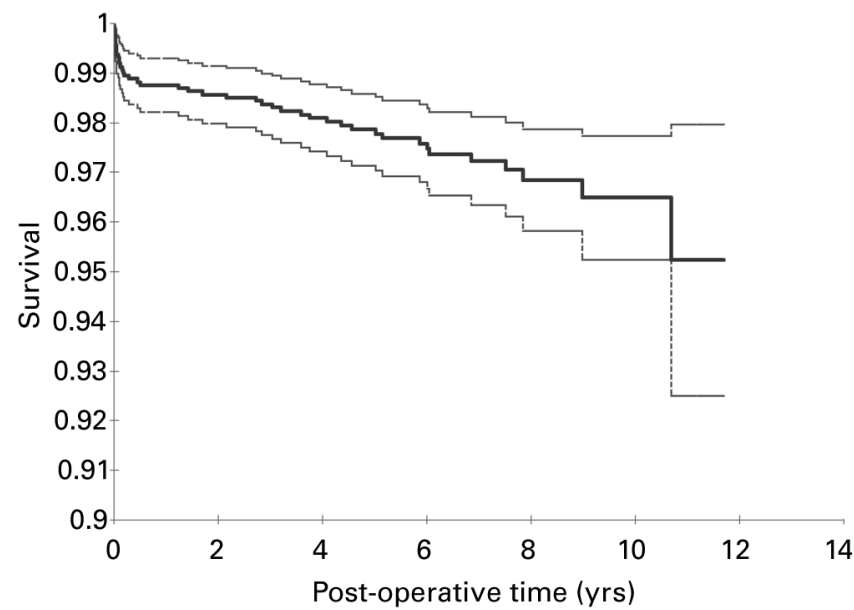

Fig. 1

Kaplan-Meier survival curve with $95 \%$ confidence interval for non-obese patients undergoing total hip replacement.

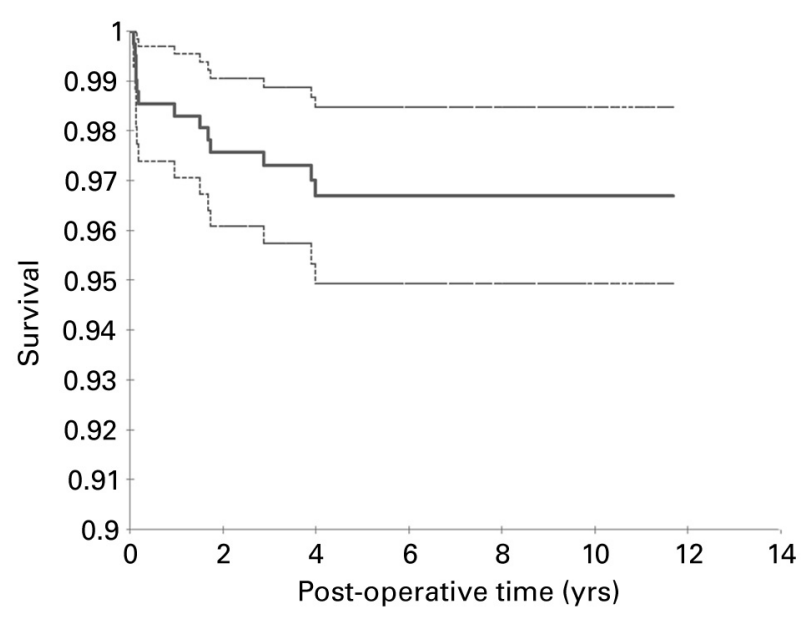

Fig. 2

Kaplan-Meier survival curve with $95 \%$ confidence interval for obese patients undergoing total hip replacement.

components of the HHS significantly reduced in the obese group apart from pain. We believe that the main reason for this difference related to a reduced range of movement because of soft-tissue apposition occurring in extreme positions, which was likely to impact on the function and activity scores. The independently assessed range of movement also pointed to a significant difference between the groups. Despite these differences, the overall satisfaction with surgery was virtually the same. A potential weakness of our clinical assessment was the lack of pre-operative scores for comparison. It is possible that the obese patient began with a lower score and might have obtained a similar relative improvement. However, it is likely that the relationship between clinical scores and obesity is far from simple. Obe-

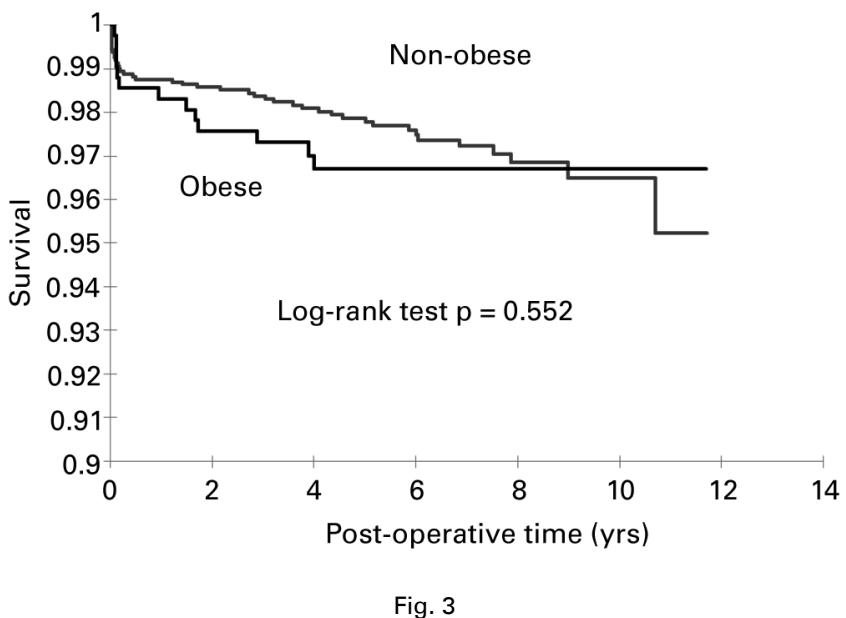

Kaplan-Meier survival curve for obese and non-obese patients undergoing total hip replacement.

sity has been shown to have broad associations with conditions detrimental to health which may adversely influence the hip score. These include depression, chronic fatigue, insomnia ${ }^{16}$ and the self-reporting of pain. ${ }^{17}$

A comprehensive radiological assessment of both the femoral and acetabular components showed no significant differences between the groups. We should expect longer term survival with good osseointegration of our cementless implants. Additionally, the predominant use of ceramic bearings in our patients should minimise the volume of wear debris and aseptic loosening. ${ }^{18}$ It has also been argued that because wear is a function of use and obese patients have a tendency to reduced activity levels, ${ }^{19}$ this would counteract any higher joint forces from increased load.

Several studies have examined the early outcome and perioperative complication rates in obese and non-obese patients. There is little evidence from these to suggest that the obese patient is at significantly increased risk of early postoperative complications. ${ }^{6,7,20-22}$ The literature on the clinical and radiological outcome in relation to obesity is limited. Several short term follow-up studies have failed to show a significant difference between non-obese and obese groups. ${ }^{8,23}$ Moran et $\mathrm{al}^{6}$ found a lower HHS in their obese group at six and 18 months but no difference in the ShortForm 36 scores. A medium term study at five years by Andrew et $\mathrm{al}^{9}$ showed no differences in the clinical outcome and radiological analysis of 1421 cemented hips but they did not perform a survival analysis. Furthermore, the study had considerable limitations with incomplete data for $25.5 \%$ and had many confounding variables associated with a multicentre trial including different hospitals, surgeons, approaches, acetabular implants, bearings and assessors.

We do not wish to underestimate the challenges presented by the obese patient with regard to patient handling, nursing care, surgical exposure and the management of comorbidities. Nevertheless, our study has shown that 
there would appear to be no justification for withholding THR because of concerns about the medium-term outcome. In conclusion, obese patients may be advised that despite a lower clinical score, they should expect survival of the implant and satisfaction equivalent to those of nonobese patients.

No benefits in any form have been received or will be received from a commercial party related directly or indirectly to the subject of this article.

\section{References}

1. No authors listed. Obesity: preventing and managing the global epidemic, technical report series 894. Part 1: the problem of overweight and obesity: defining the problem. World Health Organisation 2000:6-15.

2. Fehring TK, Odum SM, Griffin WL, Bohannon Mason J, McCoy TH. The obesity epidemic: it's effect on total joint arthroplasty. J Arthroplasty 2007;22(Suppl 2):71-6.

3. Changulani M, Kalairajah Y, Peel T, Field RE. The relationship between obesity and the age at which hip and knee replacement is undertaken. J Bone Joint Surg $[\mathrm{Br}]$ 2008;90-B:360-3.

4. Haverkamp D, de Man HR, de Jong PT, van Stralen RA, Marti RK. Is the longterm outcome of cemented THA jeopardized by patients being overweight? Clin Orthop 2008;466:1162-8.

5. McLaughlin JR, Lee KR. The outcome of total hip replacement in obese and nonobese patients at 10 to 18 years. J Bone Joint Surg [Br]2006;88-B:1286-92.

6. Moran M, Walmsley P, Gray A, Brenkel IJ. Does body mass index affect the early outcome of primary total hip arthroplasty? J Arthroplasty 2005;20:866-9.

7. Ibrahim T, Hobson S, Beiri A, Esler N. No influence of body mass index on early outcome following total hip arthroplasty. Int Orthop 2005;29:359-61.

8. Lehman DE, Capello WN, Feinberg JR. Total hip arthroplasty without cement in obese patients. J Bone Joint Surg [Am] 1994;76-A:854-62.

9. Andrew JG, Palan J, Kurup HV, et al. Obesity in total hip replacement. J Bone Joint Surg [Br] 2008;90-B:424-9.
10. Harris WH. Traumatic arthritis of the hip after dislocation and acetabular fractures: treatment by Mold arthroplasty. J Bone Joint Surg [Am] 1969;51-A:737-55.

11. Johnston RC, Fitzgerald RH, Harris WH, et al. Clinical and radiological evaluation of total hip replacement: a standard system of terminology for reporting results. $J$ Bone Joint Surg [Am] 1990;72-A:161-8.

12. Gruen TA, McNeice GM, Amstutz HC. Modes of failure of cemented stem type femoral components: a radiographic analysis of loosening. Clin Orthop 1979;141:17-27.

13. Engh CA, Massin P, Suthers KE. Roentgenographic assessment of the biologic fixation of porous surfaced femoral components. Clin Orthop 1990;257:107-27.

14. Bourne R, Mukhi S, Zhu N, Zeresteci M, Marin M. Role of obesity on the risk for total hip or knee arthroplasty. Clin Orthop 2007;465:185-8.

15. Flugsrud GB, Nordsletten L, Espehaug B, et al. The impact of body mass index on later total hip arthroplasty for primary osteoarthritis: a cohort study in 1.2 million persons. Arthritis Rheum 2006;54:802-7.

16. Patterson RE, Frank LL, Kristal AR, White E. A comprehensive examination of health conditions associated with obesity in older adults. Am J Prev Med 2004;27:385-90.

17. Heim N, Snijder MB, Deeg DJ, Seidell JC, Visser M. Obesity in older adults is associated with an increased prevalence and incidence of pain. Obesity 2008;16:2510-17

18. Lusty PJ, Tai CC, Sew-Hoy RP, et al. Third-generation alumina-on-alumina ceramic bearings in cementless total hip arthroplasty. J Bone Joint Surg [Am] 2007;89A:2676-83.

19. McClung CD, Zahiri CA, Higa JK, Amstutz HC, Schmalzried TP. Relationship between body mass index and activity in hip and knee arthroplasty patients. J Orthop Res 2000;18:35-9.

20. Dowsey MM, Choong PFM. Obesity is a major risk factor for prosthetic infection after primary hip arthroplasty. Clin Orthop 2008;466:153-8.

21. Patel VP, Walsh $\mathbf{M}$, Sehgal B, et al. Factors associated with prolonged wound drainage after primary total hip and knee arthroplasty. J Bone Joint Surg [Am]2007;89-A:33-8.

22. Namba RS, Paxton L, Fithian DC, Stone ML. Obesity and peri-operative morbidity in total hip and knee arthroplasty patients. J Arthroplasty 2005;7(Suppl 3):46-50.

23. Chan CLH, Villar RN. Obesity and quality of life after primary hip arthroplasty. $J$ Bone Joint Surg [Br] 1996;78-B:78-81. 